\title{
EXILIADAS CHILENAS: UNA APROXIMACIÓN DE GÉNERO EN LAS MEMORIAS DEL EXILIO
}

\author{
CHILEAN WOMEN EXILIED: AN \\ APPROXIMATION OF GENDER IN THE \\ MEMORIES OF EXILE
}

\author{
Carolina EsPINOZA CARTES \\ UNED
}

Resumen: El exilio chileno provocado tras el golpe de estado que significó el fin de la Unidad Popular, empujó al exterior a cerca de 200.000 personas entre 1973 y 1977 y en total a 400.000 personas, si se considera el final de la sanción en 1988. Un tercio de esa diáspora lo constituyeron mujeres, quienes salieron de Chile rumbo a los países más emblemáticos como Argentina, Canadá, México, Suecia, Noruega, Francia o España después de un periodo de persecución, represión, tortura y en muchos casos, prisión. En el artículo se analiza cómo esas mujeres vivieron el exilio solas o junto a sus familias, bajo tres ejes temáticos: la llegada al país de acogida, la familia y las relaciones afectivas y sus militancias y activismo politico.

Palabras clave: Exilio, Mujer, Memoria, Exilio Chileno, Golpe de Estado en Chile, Unidad Popular, Salvador Allende, Incorporación laboral de la mujer, Militancias, Activismo Político.

AвsтrAct: The Chilean exile after the coup d'état that meant the end of the Popular Unity, pushed about 200.000 people abroad between 1973 and 1977 and a total of 400.000 people, considering the end of the sanction in 1988. A third of the exile was constituted by women, who left Chile for countries such as Argentina, Canada, Mexico, Sweden, Norway, France or Spain after suffering persecution, repression, torture and in

${ }^{*}$ Candidata a Doctora en la Universidad Nacional de Educación a Distancia, UNED. carolina.reportera@gmail.com 
many cases, prison. This paper analyzes how these women lived in exile alone or with their families, under three thematic axes: the arrival in the host country, the family and affective relationships, and their militancy and political activism.

Keywords: Exile, Woman, Memory, Chilean Exile, Coup in Chile, Popular Unity, Salvador Allende, Labor Incorporation of Women, Militancias, Political Activism.

\section{Introducción}

El golpe de Estado sucedido en Chile el 11 de septiembre de 1973, que culminó de manera abrupta con el gobierno del socialista Salvador Allende e impuso posteriormente una dictadura de 17 ańos, tuvo como resultado no sólo una estela de muerte, tortura y desapariciones ${ }^{1}$. Además, una práctica común a sus homólogas en América Latina fue el exilio, una experiencia compartida con dos millones de latinoamericanos entre 1960 y $1990^{2}$.

Mientras el exilio tiene una larga historia en América Latina, antes de 1959 estaba reservado principalmente para algunos líderes que perdían poder en las luchas políticas internas o golpes militares. Luego del triunfo de la Revolución Cubana, América Latina fue testigo de un nuevo fenómeno de exilio masivo por motivos políticos.

Las dictaduras militares en Brasil (1964-1985), Uruguay (1973-1984) y particularmente la de Argentina (1976-1983), utilizaron el terror de Estado a diversos niveles, incorporando dentro de las estrategias para destruir a sus

\footnotetext{
1 La dictadura de Augusto Pinochet se prolongó entre el 11 de septiembre de 1973 y el 11 de marzo de 1990, dejando a su haber más de 40.000 víctimas, de las cuales 3.065 están muertas o desaparecidas (Cifras de la Comisión Asesora Presidencial para la calificación de Detenidos Desaparecidos, Ejecutados Políticos y Víctimas de Prisión Política y Tortura (llamada coloquialmente Comisión Valech II), contemplada en la Ley No 20.405 publicada el 1 de diciembre de 2009 y creada por la presidenta Michelle Bachelet mediante el Decreto Supremo No 43, publicado el 5 de febrero de 2010. Los resultados fueron dados a conocer el 18 de agosto de 2011. Se creó con la finalidad de abrir un nuevo plazo para el reconocimiento de las víctimas que no se presentaron o no fueron reconocidas por las anteriores Comisión Rettig (1992), la Corporación Nacional de Reparación y Reconciliación o por la Comisión Valech I (2004).

2 Cifra estimativa del Alto Comisionado de las Naciones Unidas para los Refugiados (ACNUR).
} 
antagonistas, la institucionalización del exilio masivo. Posteriormente en Bolivia y Paraguay también se incrementó la represión en los 80 creando pequeños flujos de exiliados. Una violenta insurrección contrarrestada con represión en Perú durante los años 80 y la exacerbación de una guerra civil de largo aliento en Colombia en los 90, agregaron su aporte a la larga lista del exilio sudamericano.

En este contexto se presenta el golpe de estado chileno, un fin abrupto del proyecto de la Unidad Popular compartido por la generación de 1968, que se siente predestinada a cambiar al mundo, impulsada por los cambios sociales que vive desde que nació en un mundo polarizado por la Guerra Fría. Para los jóvenes que participaron en esta experiencia, el cambio de sociedad era realmente posible, al igual que los cambios más radicales que Allende quiso implementar en su gobierno: nacionalización del cobre, aceleración de la reforma agraria y la nacionalización de las principales industrias, sin vislumbrar la enorme resistencia que puso desde el principio el sector conservador en Chile, que no estaba dispuesto a perder sus privilegios (Winn, 2013).

A las violaciones a los derechos humanos y a la decepción frente al fracaso de la experiencia popular, se le suma la sanción quizá menos reconocida ${ }^{3}$, dentro de todas las que implementó la dictadura cívico militar en Chile. El exilio, ya sea para salvar la vida o como conmutación de la pena de presidio, también tuvo consecuencias dolorosas en la población que lo vivió, hasta su fin oficial en $1988^{4}$.

Con sus fronteras cerradas y el transporte internacional suspendido, aproximadamente 3.500 personas optaron por refugiarse en distintas representaciones diplomáticas. Los militares bloquearon las embajadas que brindaban asilo, pero la Iglesia Católica, algunas iglesias protestantes y organismos tales como la Agencia de Naciones Unidas para los Refugiados (ACNUR), el Comité

\footnotetext{
3 En las tres comisiones de reparación -Informe Rettig y Comisiones Valech I y II- redactadas desde el retorno de la democracia en Chile en 1990, ninguna reconoce el exilio como violación a los derechos humanos. Los exiliados que aparecen en los informes, lo hacen en su condición de ex torturados o ex presos políticos y en base a esta categoría fueron compensados.

4 La prohibición de entrada al país para los exiliados se levantó en 1988 meses antes de que Pinochet convocara a una consulta nacional con la intención se perpetuarse por otros ocho ańos. Para ese entonces, muchos de los chilenos que llevaban 15 años en el exilio se tuvieron que enfrentar a la interrogante de retornar a un país del que no eligieron irse, o afincarse (Espinoza, 2005: 13)
} 
Intergubernamental para las Migraciones Europeas (CIME) o la Cruz Roja Internacional, lograron salvoconductos y pasajes para que otros pudieran salir al extranjero.

No existe posibilidad de ofrecer cifras reales de la población que salió al exilio tras el golpe de Estado. Según la Liga Chilena de Derechos del Hombre, fueron 400.000 los chilenos y chilenas que debieron abandonar el país por razones políticas, cifra que duplica a las entregadas por otros organismos. De acuerdo a los datos manejados en 1990 por la Oficina Nacional de Retorno y el Servicio Universitario Mundial, los exiliados políticos representaban alrededor de 200.000 personas dispersas entre los cinco continentes. Esta cifra del exilo político es cercana a la de la Vicaría de la Solidaridad ${ }^{6}$, que registra unas 260.000 personas obligadas a vivir fuera del país por razones políticas. Sin embargo, a partir de las propias fuentes de la Vicaría, la experta Carmen Norambuena calcula que habrían salido del país 408.000 personas. (Horvitz, 2017: 34).

El régimen militar hizo del exilio forzado una política central de su misión de erradicación de la izquierda. En algunos casos, la dictadura impuso además a un grupo de exiliados, sanciones mayores como la privación de la nacionalidad. A los pocos meses de asumir, el régimen avaló la «legalidad» del exilio, firmando resoluciones basadas en el Decreto Ley 81 de 1973 y el Decreto Ley 604 de 1974, que facultaba al gobierno de Pinochet para disponer la expulsión o el abandono del país de determinadas personas, fueran estas nacionales o extranjeras. Además, se dictó el Decreto 504 de 1975 pactado con organismos internacionales de derechos humanos como ACNUR, CIDE, Cruz Roja Internacional que actuaron conjuntamente con el Comité Pro Paz y luego la Vicaría de la Solidaridad, que permitió la salida de los presos que estaban en los campos de concentración.

\footnotetext{
5 La Oficina Nacional de Retorno se crea el 20 de agosto de 1990, mediante la aprobación de la Ley 18.994. Entre sus objetivos está el de estudiar, proponer e impulsar la aplicación de planes, programas y proyectos dirigidos a facilitar la reinserción social de los exiliados que tengan o hayan tenido la nacionalidad chilena, así como de los hijos nacidos en el extranjero de padre o madre exiliados que sean o hayan sido chilenos, que retornen o hayan retornado al territorio nacional. Para los efectos de esta ley, se consideran exiliados las personas condenadas a penas privativas de libertad que obtuvieron la conmutación de esas sanciones por la de extrańamiento, en virtud de lo dispuesto en el decreto supremo N. ${ }^{\circ}$ 504, de 1975 , del Ministerio de Justicia las expulsadas u obligadas a abandonar el territorio nacional por resolución administrativa; las que, luego de viajar normalmente al extranjero, fueron objeto de prohibición de reingresar a Chile".

6 Cifras del archivo y centro de documentación de la Fundación de Documentación y Archivo Vicaría de la Solidaridad (FUNVISOL), consultadas en octubre de 2018.
} 
Desde junio de 1975 se acogieron a este decreto 1.205 personas condenadas por delitos políticos en los tribunales militares y hasta octubre de 1976 se trató de 1.082 , lo que equivalía al $90 \%$ de las personas ${ }^{7}$.

Argentina, Suecia, Noruega, México, Canadá, Perú, Francia y España fueron los países que más recibieron exiliados chilenos. Tras el primer año del golpe, hubo movimientos posteriores entre países del exilio y quienes se exiliaron en primer lugar en Argentina o Perú, debieron moverse rápidamente cuando la dictadura se extendió también hacia esos países. En Europa, problemas de adaptación al idioma y a la cultura, significaron nuevos desplazamientos de exiliados a países de habla hispana, donde el choque cultural era menor.

Los estudios que abordan el exilio chileno, se centran en los aspectos psicológicos de los exiliados, especialmente focalizados en su retorno y dificultades de reinserción en el Chile de los años noventa ${ }^{8}$. Otra dimensión ampliamente estudiada es la producción cultural del exilio ${ }^{9}$, que va desde las revistas culturales y o de pensamiento, hasta la producción literaria o ensayística de autores fuera del país.

Sin embargo, hasta en las dimensiones más estudiadas, la presencia de la mujer -que representó el 30 por ciento del exilio chileno ${ }^{10}$ - a través de testimonios, relatos, biografías o investigaciones psico-sociológicas es escasa, silenciando una perspectiva enriquecedora, que pone el foco en una lucha política condicionada por las reivindicaciones de la mujer y su rechazo al rol histórico pasivo que le asigna la sociedad y que enfatiza en su papel reproductor. Las experiencias personales de las mujeres con la represión y el exilio -espacio privado- sirven

\footnotetext{
7 Cifras de la Fundación de Ayuda Social de las Iglesias Cristianas, FASIC, relacionadas con la aplicación del DL/504 sobre conmutación de penas por extrañamiento. Archivo del Museo de la Memoria. Consultado en octubre de 2018.

8 Las consecuencias del llamado «Síndrome de Ulises» patología que afecta no sólo a los exiliados, sino a muchos inmigrantes, son estudiadas en varios tratados médicos a principios de los años 90. Otro tipo de estudio es el que se deriva de los programas de asistencia psicológica a la que se compromete el primer informe de Verdad y Reconciliación y que tiene que ver con la reinserción de los exiliados retornados. El más conocido, el programa PRAIS.

9 La producción cultural realizada desde por exiliados comprende libros, autobiografías, novelas, poesía, artículos, ensayos y revistas culturales. Dentro de estas últimas, destacan dos: Revista Araucaria editada desde 1976 a 1994, primero en París y luego en Madrid y la revista de pensamiento Chile América editada en Roma desde 1976 a 1986.

10 Cifra estimativa de la Oficina Nacional de Retorno (1991).
} 
de aliciente para unirse, organizarse y protestar masivamente -espacio públicoproduciendo discursos de alegato contra el régimen que cobran mayor fuerza.

Las voces femeninas interpelan la violación de los derechos humanos, asumen la sobrevivencia familiar, cuestionan los modos de hacer política de los partidos y reponen la discriminación y subordinación de las mujeres como una expresión más allá del autoritarismo que se ha apoderado de la sociedad (Valdés, 2000: 220).

El papel de la mujer ha sido eclipsado por los testimonios épicos de los hombres o del exilio intelectual, que pone un doble sesgo a la participación activa de la mujer en el extranjero. A 45 años del inicio del exilio chileno, es hora de que se revierta esta situación y se den a conocer otras memorias sueltas (Stern, 2001) que entregan nuevas formas de conocer y percibir la violencia y las consecuencias del destierro. Se trata de rescatar las memorias plurales y experiencias de minorías sociales que desafían las versiones hegemónicas del pasado y rompen con el blanqueo de la historia nacional (Hirsch, 2015: 210).

Según afirma Ana Corbalán en Memorias Fragmentadas (2016), es a partir de esta exclusión histórica desde donde se puede interpretar el activismo de las mujeres que luchan contra las dictaduras.

Existe un silencio en torno a las mujeres exiliadas, encarceladas, oprimidas o ajusticiadas que también contribuyeron a los procesos de redemocratización de sus países y participaron activamente en la resistencia frente a los regímenes totalitarios. Las mujeres han sufrido especial desatención y han sido confinadas a un papel secundario en la historiografía oficial de sus respectivos países. Aunque reivindiquen sus luchas revolucionarias, aún se encuentran en una posición marginada en la historia (Corbalán, 2016: 13).

Las mujeres chilenas en el exilio continuaron con su militancia y activismo político, incluso en situaciones de adversidad idiomáticas y culturales, pudieron sacar adelante a sus familias, postergando en muchos casos el desarrollo intelectual al aceptar trabajos en el país de acogida para los que estaban sobrecualificadas. Se preocuparon de la escolarización de sus hijos, formaron nuevos lazos y redes sociales, e hicieron grandes aportes a la sociedad de acogida, sin descuidar el objetivo primario de la lucha contra la dictadura. 
La presente publicación retrata una investigación en curso, que tiene por objetivo recuperar el relato de las mujeres exiliadas chilenas en el mundo y analizar sus testimonios y discursos, en busca de marcas que permitan enfatizar el activismo femenino contra los regímenes autoritarios. Intenta realizar una aproximación de género en el destierro, reivindicando la visibilidad de las mujeres marginadas y enfatizando los aportes que hicieron en sus países de acogida. Los testimonios se organizan en base a tres ejes temáticos, tales como la llegada al país del exilio, las relaciones familiares y afectivas, y la militancia.

La metodología utilizada para esta investigación ha sido principalmente el uso de fuentes orales ${ }^{11}$, para romper el doble sesgo anteriormente señalado, donde las experiencias del exilio son contadas principalmente en clave literaria, reduciendo el relato a las mujeres intelectuales. La investigadora ha entrevistado personalmente a mujeres que debieron afrontar la experiencia del exilio desde diferentes niveles culturales o posiciones socioeconómicas. Además, en el caso de las dictaduras surgidas en Latinoamérica, la ausencia de documentos escritos por razones de seguridad, tanto de los perpretadores como por parte de las víctimas, obliga a que si se desea registrar la historia de esta etapa, se tenga que recurrir necesariamente a las fuentes orales.

\section{Mujeres exiliadas}

Muchas veces la memoria y el relato del exilio se registra en clave masculina. Son los hombres, por lo general intelectuales o con algún cargo de representación, los encargados de contar en reportajes, artículos académicos o libros de investigación o biográficos, el relato épico del exilio. En esos relatos hay marcas de heroicidad, fechas de hitos importantes, dejando entrever en todo momento el privilegio de haber sido ser testigos de la historia. Por ejemplo, en la narración del Último día de Salvador Allende, narración homónima del asedio al Palacio de la Moneda el día 11 de septiembre de 1973. Su médico personal, Oscar Soto, tiene una breve mención a las mujeres que estaban ese día en el sitio en la página 82, y luego no lo hace con la misma extensión hasta la página 177, donde

11 Los testimonios citados que no ha recogido personalmente la autora, corresponden a transcripciones citadas en otros textos del exilio chileno en el mundo o a entrevistas que ha hecho la autora para documentales o libros que han tratado sobre el exilio chileno. 
se transcribe parte del discurso de Hortensia Bussi, la viuda de Allende, en su funeral que tuvo lugar 17 ańos después.

El Presidente ha estado intentando que las mujeres abandonen La Moneda. Su hija Beatriz está en los últimos meses de embarazo. Ni ella, ni Isabel (otra de sus hijas), ni Payita (su secretaria), ni Nancy, ni ninguna de las compañeras está dispuesta a obedecer. Allende, preocupado, coge el citófono y le dice a Carvajal, que está en el Ministerio de Defensa: "Almirante, le habla el Presidente le exijo que envie un vehiculo protegido para que saque a las compañeras que aún permanecen en el Palacio. Apelo a su honor de hombre y no de soldado, para que asegure la vida de estas mujeres» (Soto, 1998: 82).

Sin embargo, en el relato femenino de procesos traumáticos como las guerras, golpes de estado o el propio exilio, las marcas de la historia positivista quedan en segundo plano para hacer hincapié en la descripción de lo que encontraron en el momento del exilio, en los afectos y en cómo se siguió cultivando la relación con el país de origen. Los olores, colores, los problemas que surgieron en la vida nueva del destierro, afloran con entusiasmo en los relatos de las mujeres del exilio. Como dice la última obra de la Premio Nobel de Literatura 2015, la periodista bielorrusa Svetlana Alexiévich en su libro La guerra no tiene rostro de mujer.

Todo lo que sabemos de la guerra, lo sabemos por la voz masculina, a través de palabras masculinas. Las mujeres mientras tanto guardan silencio. La guerra femenina tiene sus colores, sus olores, su iluminación y su espacio. Tiene sus propias palabras. En esta guerra no hay héroes ni hazañas increíbles, tan solo hay seres humanos involucrados en una tarea inhumana. (Alexiévich, 2015: 10).

Invisibilidad que contrasta con la importancia de incluir la experiencia femenina en la identificación de las mujeres como sujetos con agencia histórica.

La legitimación de las historias femeninas establece un paralelismo entre lo personal y lo político, porque la experiencia vivida por estas personas es algo que conduce directamente a la lucha activa contra la opresión (Scott, 1992: 32).

En general todos los relatos relacionados con violaciones a los derechos humanos son conocidos principalmente desde una óptica masculina, una práctica 
que se ha extendido a lo largo de las investigaciones que hablan sobre procesos traumáticos en la historia chilena.

La inclusión de la perspectiva de género en las investigaciones sobre violaciones de los derechos humanos en tiempos de conflictividad militar, ha sido tardía cuando no obviada. Esa circunstancia se explica por el peso consuetudinario de la mentalidad androcéntrica en todos los ámbitos del conocimiento universal, en donde tradicionalmente se ha otorgado a la mujer un papel subsidiario (Maravall, 2012: 111).

Esta invisibilización de los relatos de mujeres en lo que se refiere a violación a los derechos humanos, se extiende además a los testimonios del exilio.

El exilio ha tendido a ser conceptualizado básicamente como una experiencia masculina, debido a que la mayoría de las personas con prohibición de ingreso eran hombres y los altos dirigentes políticos del gobierno anterior cuando regresaron, impusieron un discurso hegemónicamente masculino que se difundió a través de los medios de comunicación, desdibujando las experiencias de mujeres y niños (Rebolledo, 2010: 2).

Un invisibilización difícil de entender si se considera que históricamente la mujer ha tenido un papel protagónico en la transmisión cultural.

Tradicionalmente las mujeres han sido las transmisoras de la memoria y por tanto las prácticas de memoria tienen un aspecto de género, ya que el papel habitual de la mujer ha sido el de conservar esta memoria (Hirsch, 2015: 213).

La invisibilización y la marginación de la memoria femenina se encuentra tan arraigada, que, en algunos casos, las mujeres al ser entrevistadas ponen barreras. Se excusan en que hay demasiados recuerdos aparcados durante mucho tiempo, a los que aseguran, es doloroso volver y escudrińar. Sin embargo, cuando en ocasiones se les vuelve a pedir su testimonio, aludiendo a la escasez de versiones femeninas del exilio, y a la necesidad de reescribir su historia, el trauma se aparca por "este fin mayor», se logra franquear la resistencia inicial y acceden a contar su testimonio.

Estas mujeres pagaron con el destierro su obstinación en obtener justicia y en vivir de acuerdo con el principio de igualdad. Son modelo de lo que 
fue un comportamiento de doble frente: en lo político social y en lo político sexual (Martínez, 2007: 140).

Otras, acostumbradas a ser «hijas de» o "esposas de», al principio se sorprenden porque se les requiere, pero después de muchas preguntas de filtro, comienzan un relato distinto. Un relato que tiene que ver con memorias sueltas, que se entrelazan con la memoria emblemática (Stern, 2001). Una red de microhistorias inicialmente marginadas del discurso oficial, a través de las cuales se conoce la historia de una comunidad mayor, como una familia, un pueblo o un país.

Con todo el dolor de lo que pasó, debo decir que estoy harta que durante años, yo sea conocida como "la mamá de Rodrigo». Tengo un pasado, una militancia, unas razones que explican mi exilio, cuando me fui y ahora. Es hora de que se deje de esconder el relato de la mujer en el exilio y en las violaciones a los derechos humanos (Verónica De Negri, exiliada chilena en Washington desde 1976, en entrevista concedida a la investigadora el 23.04.19).

Existen visiones compartidas entre los recuerdos masculinos y femeninos del exilio. En ambos coincide la sensación de caos, de vivir en permanente ubicuidad - estar aquí y allí a la vez-y también la sensación de dolor que significa el destierro, el desarraigo. Sin embargo, en el modo de reaccionar, hubo maneras distintas de enfrentarse a ese desorden, mostrando las mujeres una facilidad y esmero en asumir que el tiempo transcurrido en el exilio fue un tiempo real -no un limbo- y por lo tanto había que ocuparse de asuntos reales, de asuntos cotidianos.

Se manifestó la necesidad de dar respuesta a situaciones concretas de subsistencia material y afectivas, aprender idiomas, encontrar trabajo, retomar los estudios, organizar, aunque fuera de modo precario, un espacio donde vivir, enviar los hijos al colegio, enamorarse, casarse, separarse, hacer una nueva red de amistades, y por supuesto, colaborar con las labores de resistencia y apoyo a Chile.

\subsection{Llegar a un país desconocido}

El exilio significó para las mujeres que apoyaban el proyecto de la Unidad Popular, una interrupción forzada de sus vidas y tener que empezar de cero en un ambiente muchas veces adverso y hostil. La mayoría salió precipitadamente 
del país sin disponer de medios suficientes para subsistir a medio plazo, unas por iniciativa propia ante el riesgo de ser capturadas y otras al ser expulsadas directamente por la dictadura.

Muchas de ellas habían sufrido represión a través de los métodos usados por la dictadura para alentarles a dejar el país: despidos y listas negras, cortos periodos de prisión, frecuentemente repetidos y acompañados de tortura, arrestos a miembros de la familia, allanamientos del hogar y hostigamiento en general. En algunos casos, las mujeres exiliadas debieron salir primero, dejando a sus hijos al cuidado de sus abuelos, hasta encontrar un destino estable. En otros, fue el marido el que salió primero y luego se reencontraron en el país de acogida, días o meses después, tras una tensa incertidumbre. En casos extremos, la separación se manifestó desde el principio y muchas familias se desintegraron.

La llegada intempestiva a países con diferencias radicales en la cultura y en el idioma, hizo que las exiliadas y sus familias, sufrieran procesos de adaptación. Sin embargo, en el país de acogida, la situación de las personas exiliadas fue distinta. Incluso en los casos en que se hablaba un mismo idioma, la separación y el estrés de insertarse rápidamente después de una situación traumática, está presente tanto en los relatos testimoniales como autobiográficos de las exiliadas. La llegada es una especie de "kilómetro cero», de punto de partida donde comienza el relato y siempre está presente en los testimonios, aunque estos tarden en salir a la luz. De esta manera, las entrevistas o la escritura -si se trata de relatos autobiográficos o literarios- se dan con un afán liberador, que muchos expertos atribuyen como terapéutico.

Por medio de la escritura, las voces femeninas escogen una vía de acción para seleccionar experiencias vitales y reconstruir sus memorias en el exilio. Los testimonios en el exilio son una práctica a la vez política, literaria y terapéutica (Peris Blanes, 2005: 95).

En Francia, las exiliadas chilenas fueron recibidas por el gobierno de Georges Pompidou, con una carta de bienvenida que anunciaba para los refugiados chilenos, un sistema de asignación de casas de acogida (foyers), ropa, escolarización para los niños, inmersión en el idioma francés y en algunos casos, la búsqueda de un trabajo similar al que desempeñaban en Chile. No obstante, el dolor del intempestivo desarraigo, persistía si se considera que los refugios donde se destinaban a los exiliados, constituían un gheto. 
Nuestra llegada a Francia fue dificil. El 17 de enero de 1974 llegamos a Orly nos trasladaron a un albergue en Choisy Le Roy, comuna en las afueras de Paris. Ese día sentí un frío que atravesó mi cuerpo, el frio de Paris, gris, y el frio del exilio. Pero tuvimos la suerte de ser enviados al sur de Francia, a Nimes, donde viví 6 años. Los compañeros del Partido Socialista francés, los de Partido Comunista o del Partido Radical de izquierda, los profesores que nos enseñaron el idioma, los amigos que estuvieron alli cuando necesitábamos apoyo moral y material, todo fue de una solidaridad increible. (Elsa Santander, exiliada en Francia. Extracto del libro de testimonios El asilo francés a 40 años del golpe de Estado, 2013: 34).

En Suecia, la situación fue parecida a Francia. Responsable de la salida de unos 1.300 chilenos fue el embajador de Suecia en Chile en el momento del golpe, Harald Edelstam, quien refugió en las dependencias de la embajada sueca a familias completas, a quien les abrió las puertas de la delegación diplomática para vivir allí mientras eran tramitados los salvoconductos de los perseguidos políticos. La llegada de los más de 5.000 chilenos fue un asunto de estado para el socialdemócrata Olof Palme y la inserción de los exiliados fue facilitada por la política de inmigración del gobierno de Suecia en esos años, que brindaba las condiciones materiales.

A los exiliados se nos brindó enseñanza del idioma; programas de preparación profesional para quienes estaban en edad laboral, acceso rápido a la vivienda; ayuda social y subsidios; incluso para la compra de muebles, menaje de casa o ropa (Olinda Mena, exiliada chilena en Estocolmo y militante del Partido Comunista en entrevista con la investigadora en Estocolmo el 9.09.18).

En Bélgica, también se contó con un plan de acogida que permitió a los exiliados chilenos reinsertarse, facilitándoles la continuación de estudios para las personas que los habían comenzado en Chile y ayudándoles al aprendizaje del idioma.

Tras las desapariciones de mi marido en 1973, intenté quedarme en Chile. En la vida laboral, hice cursos de dibujo técnico y empecé a trabajar para el diario "La Estrella", luego, con mucho esfuerzo, pude seguir en la universidad hasta que terminé mi carrera de dibujo técnico. El clima de la dictadura me tenia asfixiada, partí al exilio en Bélgica en 1977 y pude trabajar en lo mio. Ahora estoy jubilada luego de desempeñarme como dibujante en dos museos en Bélgica y en diversas industrias hasta 2012 (Sandra Fernández, exiliada chilena 
en Bruselas, ex militamte del Partido de Izquierda Revolucionaria, MIR en entrevista realizada por la investigadora en Bruselas el 4.11.18).

En Noruega, el estado benefactor abrió las puertas a los chilenos del exilio, acogiéndoles principalmente en las ciudades de Bergen y Oslo.

Cuando llegamos, nos dieron una casa para mi mamá y mis hermanos. La casa tenía unos muebles que habia que armar, pero los vecinos nos ayudaron. El gobierno nos escolarizó y nos enseñó el idioma. Nos dio apoyo psicológico también. Cuando llegamos a la casa que nos dieron, nos venía a visitar una asistente social y les parecía muy raro que nos ducháramos todos los dias. Nos dijeron que eso no era bueno para la piel. (Leandra Bruner, exiliada chilena en Oslo, extracto de su autobiografía Ardilla, los hilos rojos de mi memoria, 2018: 283).

Distintos movimientos sociales en torno a la Solidaridad con Chile, plataformas compuestas por ciudadanos chilenos residentes en el extranjero, agrupaciones de derechos humanos y organizaciones de cooperación internacional, dieron la primera acogida a los exiliados. Ello significó un apoyo fundamental para iniciar un nuevo proyecto vital fuera de Chile, sin el que difícilmente las exiliadas hubieran podido sobrevivir. En algunos casos, en los mismos aeropuertos de destino, Comités de Bienvenida las recibieron ocupándose de sus necesidades más inmediatas. Esto amortizó un tanto el desarraigo, pero a su vez generó una actitud distinta en la asimilación del proceso que venía, estableciéndose diferencias entre las reacciones de hombres y mujeres. Mientras los exiliados chilenos tenían sus maletas hechas detrás de la puerta, sus compañeras sospechaban que el exilio no sería cosa de unos meses y tan siquiera de algunos años.

El sentido práctico femenino, su necesidad de ponerle anclas a la vida y amoblar el cotidiano de sus familias, derivado de su responsabilidad en la reproducción, las hizo ubicarse más rápidamente en el país del exilio (Rebolledo, 2010: 12).

Para ellas, la experiencia del destierro fue dura, pero prefieren no hablar del tema y aparcarlo en su memoria, de manera tal de seguir adelante en cuestiones más prácticas, que exigían respuestas más inmediatas.

Mi marido vivía otra realidad, otro mundo. Él siempre hablaba de volver a Chile, como si estuviéramos aqui de paso y se deprimía constantemente si alguien decía lo contrario. Yo a partir del primer año lo empecé a tener claro; teníamos 
que aprender el idioma, buscar trabajo en lo que fuera para insertarnos en esta sociedad que no esperaba darnos todo en bandeja (Amanda Fernández, exiliada chilena en Roma en entrevista concedida a la investigadora el 23.02.19).

Flora Villalobos, hija de Luis Villalobos, alcalde de Chuquicamata durante la Unidad Popular, recuerda que cuando sus padres se exiliaron en Estocolmo, fue su madre quien la llevó a aprender sueco.

Viviamos en un campamento chileno por lo que no teníamos problemas de comunicación, pero fue mi mamá la que insistió y aprendimos juntas sueco en tres meses, lo que facilitó completamente mi integración (Exiliada chilena Flora Villalobos en entrevista concedida a la autora en Estocolmo el 9.05.05).

Otro rasgo característico del exilio de las mujeres, fue su capacidad para trabajar en la tarea de la resistencia, organizando eventos para visibilizar el problema chileno en el exterior, y a partir de esto, recaudar fondos para enviar a los partidos políticos que estaban en la clandestinidad en Chile.

Fuimos las mujeres chilenas en el exilio las que organizábamos eventos, cenas, peñas, para recaudar fondos para a la resistencia. Mucho discurso por parte de los hombres, pero éramos nosotras las que pasábamos a la acción (Ana María Flores, exiliada primero en la RDA y luego en Madrid en 1979, en entrevista concedida a la investigadora el 29.11.18).

Esta actitud esquiva de las mujeres para abrirse a contar su relato sobre la experiencia del destierro, puede explicarse por el hecho de que ellas desean olvidar, además, el trauma de la ruptura con la pareja que en muchos casos provocó el exilio. Las mujeres exiliadas privilegian en sus recuerdos los aspectos positivos de la experiencia del exilio: el poder tomar decisiones por sí mismas de manera autónoma -en muchos casos, por primera vez-o valorar lo que ellas mismas construyeron: casa, amistades, un mundo para sus hijos y, minimizan u «olvidan» el precio que pagaron por ello tales como el desarraigo, la postergación profesional y en algunos casos, el divorcio (Rebolledo, 2010: 13).

Ahora mi madre puede hablar de esto, pero en su momento no, porque la partida de Chile fue muy dolorosa y en nuestro caso estuvimos en Cuba y en la RDA antes de venir a Madrid. Pasamos pellejerías, en especial ella que salió de Chile con nosotros, yo y mis dos hermanos. No la recuerdo quejándose, pero si la veo en fotos y su cara lo dice todo. Hasta el tono de la piel le cambió de estar 
en permanente tensión (Marcela San Martín, hija de exiliados chilenos en Madrid en entrevista concedida a la autora el 8.06.18).

\subsection{Familia y relaciones afectivas}

Existen factores que explican las rupturas familiares o las separaciones entre parejas que partieron al exilio. Por una parte, se encuentran las parejas a las que el golpe de Estado les sorprendió en situación no consolidada, donde el proyecto de vida en pareja no estaba muy claro y el golpe precipitó esta decisión. Otras parejas no supieron sobrellevar una experiencia fuerte como la represión o la tortura. Otra causa obedeció a la situación anteriormente descrita de independencia de las mujeres que acompañaron a sus esposos al exilio y se encontraron en el país de acogida con sociedades en las que estaba recién manifestándose el movimiento feminista, lo que les hizo «abrir los ojos» y explorar los beneficios de esa independencia.

De cada diez parejas de exiliados latinoamericanos que llegaron a Canadá, siete se separaron. Muchas mujeres venían de hogares muy conservadores, donde tenian que pedirle permiso al marido hasta para comprarse un vestido. Aqui se encontraron con una sociedad que estaba viviendo uno de los movimientos feministas más fuertes de la época y eso influyó en el proceso de autonomía de esas mujeres, que empujó en algunos casos, a las rupturas matrimoniales (Patricio Henríquez, exiliado en Canadá, en entrevista concedida a la investigadora en Toronto el 11.07.05).

Hubo matrimonios chilenos que se separaron porque las mujeres comenzaron a generar sus propios ingresos y eso a sus maridos no les gustó. También muchos hombres abandonaron a sus familias por sentirse atraidos por las mujeres escandinavas y viceversa. (Nolvia Domínguez, militante del Movimiento de Izquierda Revolucionaria, MIR exiliada en Oslo, en entrevista concedida a la investigadora el 25.05.19).

En España, el contexto de acogida de las mujeres que llegaron a finales de los años setenta, no fue tan distinto al de otras exiliadas chilenas. España estaba viviendo la transición a la democracia, después de 40 ańos de dictadura nacionalcatólica. Se producían profundas transformaciones, que tendrían que desembocar en una mayor autonomía para las mujeres, ancladas durante años a un 
conservadurismo que las obligaba a exaltar su función reproductora, teniendo como máxima aspiración en cuidado de sus hijos y de la casa.

Al principio, algunos resabios de esa Espańa oscura impactaron a las exiliadas chilenas.

Nada más llegar en 1977 me impactó que muchas mujeres mayores en Madrid, vestían de negro, como ahora uno se imagina a algunas mujeres en los pueblos. También me impactó la pacatería con que se llevaba en público, una relación de pareja en esos años. Recuerdo que tuve un novio español y cuando ibamos en el metro, lo abrazaba o le tomaba la mano, yél me decía suéltame mujer, que estamos en público. Para mi esas muestras de afecto en público eran completamente normales en Chile (Pilar Santana, ex militante del Movimiento de Izquierda Revolucionaria, MIR, exiliada en Madrid en entrevista concedida a la autora el 05.06.18).

Sin embargo, esta situación fue cambiando en los primeros años de la transición, al punto de avanzar en cuestiones que llevaban años anquilosadas en la sociedad española. Para las exiliadas chilenas, encontrarse en una situación de igual a igual en la pareja en una sociedad menos conservadora, al menos en lo que se refería al mundo laboral, les abrió un mundo de posibilidades que en algunos casos no habían vivido en Chile.

La legislación que autoriza el divorcio que se aprueba en 1981, equiparando la normativa española a la de otros estados europeos, es en algunos aspectos la principal transformación que se da en el campo de los comportamientos sociales en España. También se registró ese año un aumento del nivel educativo y socioprofesional, un factor positivo esencial en el desarrollo de comportamientos igualitarios (Cabrejas, 2004: 5-8). Posteriomente en 1985, ya en el gobierno socialista, se aprobaría la ley del aborto, que despenalizaba la interrupción del embarazo en tres supuestos: riesgo grave para la salud física o psíquica de la mujer embarazada, violación y malformaciones. Esta aprobación, aunque restringida, significó una verdadera revolución en la mujer y un cambio en la concepción de los procesos de salud reproductiva en España.

Los procesos de apertura que encontraron las exiliadas en países europeos y de América del Norte, les abrieron un mundo de posibilidades que comenzaron a explorar primero, con la independencia laboral. Su deseo por obtener la independencia económica de sus maridos, les llevó a buscar trabajo y a obtenerlo antes 
que ellos. Al principio se trataba de un trabajo precario en el sector servicios, sin embargo, poco a poco fueron escalando posiciones, hasta lograr trabajar en la profesión para la que habían estudiado. La situación fue más difícil si la mujer venía al exilio sin pareja, ya que carecía de una red familiar para cuidar a los niños, lo que hacía difícil la continuación de estudios.

La dictadura significó que interrumpiera mis estudios de derecho en la Universidad de Chile, y ante el panorama de persecución, decidi autoexiliarme en Barcelona, donde ya vivia mi hermana. Aqui trabajé de todo. De chacha, de quiosquera y hasta de encuestadora, era difícil salir a trabajar y dejar sola en casa a mi hija de 7 años. Le tenía que decir, no abras la puerta a nadie, dejarle comida fría, por temor a que no encendiera la cocina, etc. Fue muy duro, porque tuvo que madurar muy pronto, hasta el día de hoy eso me produce dolor. Me quedé con el trabajo de encuestadora, para una empresa que pretendía descubrir el comportamiento de una sociedad que despertaba. Eran mujeres quienes me abrian la puerta de su hogar y aunque comenzábamos a hablar de tendencias politicas, me terminan confesando la gran represión que aún vivía la mujer en España a finales de los años setenta. (Marina Caballero, exiliada en Barcelona en 1977, en entrevista concedida a la investigadora el 27.06.18).

Y es que la crianza de los hijos, cuando los había, constituía en el exilio una responsabilidad exclusiva de las mujeres. Muchas de ellas sienten remordimientos por haberles dado un papel secundario en el exilio, supeditando la crianza a un fin mayor como la lucha contra la dictadura ${ }^{12}$.

Siento que la mayor deuda de Chile con el exilio es en torno a los hijos. Durante mucho tiempo fueron apátridas, la noción de Chile que tenían la construyeron sobre nuestros recuerdos y ya cuando habia que volver, era demasiado tarde. (Alicia Téllez, exiliada en México, Cuba y finalmente en Madrid en 1975 en entrevista concedida a la autora el 7.06.18).

Hubo un partido, el MIR, que obligó a sus militantes a volver a Chile aún en dictadura, para hacer la lucha «desde dentro». Para que el cuidado de los hijos que permanecieron en los lugares del exilio fuera una experiencia colectiva, se

12 De la crianza de los hijos en el exilio se ha tratado mucho en la filmografía documental chilena reciente. No es objeto de este trabajo entrar en profundidad en el tema en este trabajo, sin embargo se sugiere ver los documentales, hechos por mujeres: Calle Santa Fe (Carmen Castillo, 2007, 63 minutos) y El edificio de los chilenos (Macarena Aguiló, 2013). 
creó el «Proyecto Hogar», una comunidad de hijos a cargo de monitores, que nació en Bélgica y concluyó en Cuba. De este proyecto, madres e hijas tienen a día de hoy, sensaciones encontradas.

Creo que cuando hicimos el proceso de retorno, el partido estuvo ausente en el sentido de que no tuvimos los espacios de conversar, socializar ni los espacios colectivos de llorar, porque lo hicimos, y mucho. Pero no me arrepiento de lo que hicimos, si asumo lo que dicen todos nuestros hijos, que nos recriminan que no fueron consultados (Mujer militante del MIR que participó en el Proyecto Hogar en el documental Calle Santa Fe de Carmen Castillo, 2007).

Nunca pude entender de que mi mamá nos dejara, nunca se lo pude perdonar. Ahora la entiendo realmente, entiendo su postura y lo que quiso hacer, pero inconscientemente yo no lo puedo superar. Cuando discuto con ella el primer punto que sale es eso. Durante mucho tiempo pensé que este proyecto era el gran error del MIR. Igual lo pasamos bien con los otros niños, pero habia una pena muy grande por el abandono y por ser considerados «los segundos» de la historia (Hija de militante del MIR que participó en el Proyecto Hogar en el documental Calle Santa Fe de Carmen Castillo, 2007).

No sólo la crianza fue supeditada por la militancia. También la maternidad quedó en segundo plano ante la urgencia de conseguir un trabajo, en especial cuando pasó el tiempo y las ayudas y subvenciones se fueron extinguiendo. La excesiva duración de la dictadura, trajo consecuencias también más adelante, a la hora de pensar en el retorno ${ }^{13}$. Tras 17 años, muchos hijos del exilio eran adolescentes, sentían que se les obligaba a marcharse a un país que no conocían y eso complicó principalmente en las mujeres exiliadas, la decisión del retorno.

Pensamos en volver, pero el problema es que era una decisión y mis hijas deberían haber tenido unos 15 o 16 años y no estaban por la labor. (Ana María

13 El 1 de septiembre de 1988, por medio del decreto 203 del Ministerio del Interior de Chile se puso fin al exilio: «(...)Déjense sin efecto todos los decretos y decretos supremos exentos que, dictados en virtud de las atribuciones conferidas por el Artículo $41 \mathrm{~N}^{\circ} 4$ de la Constitución Política de la República disponen la prohibición de ingreso al territorio nacional de las personas que en ellos se mencionan(...)». Esta medida fue claramente una maniobra política de la dictadura, para «blanquear» su rostro ante el plebiscito del 5 de octubre de 1988, que posteriormente perdió. 
Flores, exiliada en Madrid en entrevista concedida a la investigadora en el documental La alegría de los otros, 2008, Chile, España, 45 minutos).

Chile es el país de sus padres, es un país casi mítico del que han escuchado las peores cosas (tortura, represión y miseria) o las más grandes maravillas (paisajes, familia, estilo de vida) (Bolzman, 1993: 23).

Fue una discusión grande, pero no estábamos preparados en ese momento para regresar, aunque muchas personas lo hicieron. El triunfo del NO en el plebiscito fue importante, pero no habia un cambio radical en ese momento (Ana Dobson, exiliada en Canadá en entrevista concedida a la investigadora en Quebec, para el documental La alegría de los otros).

El tema de regresar estaba muy presente en los padres y uno a veces también pensaba que teníamos que regresar. Pero ese proyecto no era nuestro, era el proyecto de nuestros padres (Alejandra Quezada, hija de exiliados en Canadá en entrevista concedida a la investigadora en Quebec, para el documental $L a$ alegría de los otros).

La gran deuda pendiente que denuncia la mayoría de las exiliadas es la recomposición de los afectos. Ésta en algunos casos, sigue pendiente, porque, aunque han pasado los años, muchas confiesan tener el corazón dividido entre el país que les vio nacer y en el que intentaron una revolución democrática, y el país que les tendió la mano y en el que descubrieron otros valores.

Es posible quizá después del retorno físico, la existencia translocal, como una forma de vida y de pensamiento. Pero el dilema del exilio, basado en la noción de una conexión significativa con el hogar, bien puede continuar en el tiempo e independientemente del lugar en que vivan las exiliadas (Eastmond, 1997).

Las mujeres que retornaron a Chile entre 1988 y 1990 se encontraron con un escenario un tanto adverso, debiendo enfrentar periodos de desadaptación de ellas y sus familiares, así como también la evidencia de los años en el exterior que se manifestó en dificultades para recomponer las redes sociales. La recuperación del tejido social de las exiliadas se tornó como una tarea compleja, dado que parte de sus amistades y familiares estaban presos, habían muerto o seguían en paradero desconocido. Esta situación dejó literalmente a cientos de mujeres en la más absoluta soledad, razón que explicaría sus acercamientos posteriores a las organizaciones de mujeres en Chile. 
Las exiliadas que se quedaron en sus destinos de acogida al jubilarse, se volcaron más hacia el activismo, al tener más tiempo para ello. Algo que con el trabajo a diario no podían realizarlo en profundidad.

Me jubilé hace 2 años después de trabajar toda la vida en Madrid en un colegio. Ahora me puedo dedicar a las cosas del Partido, sigo las noticias desde Chile, pero también aqui organizamos actos, como el que recuerda a Allende cada 11 de septiembre, pero también actos culturales y de reivindicación de la memoria histórica. Estas actividades las hacemos ahora de manera espontánea un grupo de exiliados que nos llamamos "Grupo de chilenos de izquierda en Madrid» (Erica Araya, exiliada chilena y militante del Partido Comunista, en entrevista concedida a la autora el 12.04.19)

También fueron las primeras que se ocuparon de mantener los lazos con las familias en Chile, al principio a través de cartas y llamadas, y luego -desde los años 2000- de Internet, Skype o en el último tiempo, a través de Whatsapp o Facebook.

Me comunico habitualmente con mis sobrinos nietos por Skype, los veo crecer, sus cumpleaños, su primer día en el cole, no me pierdo ni una. Al principio esto era más dificil porque una tenia que ir a un locutorio y abi no tienes privacidad, la gente gritando, no se puede. Prefería la tarjeta, pero eso te exigía tener un numero fijo en la casa. Al final, fuera lios y con lo de Skype es mucho mejor la sensación (Nélida Molina, exiliada chilena en Madrid, en entrevista concedida a la autora el 2.02.19).

Serán las tecnologías de la información, las que también las volverán a acercar al quehacer de sus partidos de origen, al contacto con antiguos compañeros de militancia y a potenciar su activismo latente.

\subsection{Militancias y activismo}

No todas las mujeres militaban un partido político en el Chile de 1973. Y aunque la militancia se incrementó desde que la mujer obtuvo el voto sin 
restricciones en $1949^{14}$, afiliarse a un partido político para una mujer implicaba una acción comprometida y una dedicación a la que en esa época no todas podían optar tan libremente. Otras, no formalizaron su militancia con un carné político, pero sí con una simpatía que quedó reflejada en la adhesión al gobierno de la Unidad Popular (1970-1973) periodo en que Salvador Allende propició un desarrollo de la mujer importante en Chile, en comparación con el conservadurismo de gobiernos anteriores.

Aunque las 40 medidas de la Unidad Popular, el programa de gobierno de Allende, no abordaba de manera explícita el problema de la discriminación de la mujer, sí que se incluyeron algunos aspectos importantes hasta entonces ignorados como la igualdad jurídica entre sexos: «En el plano de los sueldos y salarios se eliminarán todas las diferencias entre hombres y mujeres (...) la mujer casada gozará de plena capacidad jurídica» ${ }^{15}$.

El Gobierno de la Unidad Popular no pudo excluir en su lucha de clases, una aproximación a la igualdad de género. Así lo recoge el artículo de Vania Bambirra, escrito para la revista Punto Final, titulado «La mujer chilena en la transición al socialismo», donde se considera urgente provocar unas profundas transformaciones sociales, que terminen con la objetualización de la mujer.

Siempre es inevitable que, en cualquier proceso revolucionario, coexistan transformaciones profundas en el nivel económico con características sumamente viejas y reaccionarias en las formas más preliminares de convivencia social, como por ejemplo la mantención por un cierto período de la condición de objeto de la mujer (Extracto del artículo «La mujer chilena en la transición al socialismo", Revista Punto Final, junio de 1971).

El programa de gobierno de la Unidad Popular incluyó varios aspectos importantes que hasta entonces habían sido ignorados y aunque el problema de la discriminación hacia la mujer y la concepción de su rol en la vida políticasocial no se abordó en profundidad, sí se avanzó en temas de igualdad jurídica y equidad salarial, buscando eliminar todas las diferencias.

14 El 8 de enero de 1949, en un acto público en el Teatro Municipal de Santiago, con la asistencia del Presidente de la República, Gabriel González Videla, Ministros de Estado y autoridades se firma la ley que autoriza el voto político para la mujer (Eltit, 1994: 45).

15 Programa de gobierno de la Unidad Popular, 17.12.69. 
$Y$ serán los trabajadores de la industria los que impidan al mal patrón discriminar en la remuneración que debe recibir la mujer. No sólo será la mujer la que debe defender sus derechos, sino que será la obligación de los trabajadores no permitir, no tolerar, no aceptar que se la explote más. (Salvador Allende, discurso de campaña, julio de 1970).

También se facilitó un mayor acceso de las mujeres a la educación y la salud, especialmente con las campesinas analfabetas que tenían los mayores indicadores de pobreza en el país. En lo que se refiere al acceso a la universidad, Allende aumentó las becas para mujeres con bajos recursos que contaran con méritos académicos. Hay que mencionar que, aunque las carreras universitarias elegidas por las mujeres tendían a reproducir las áreas tradicionales de trabajo asignadas por la socialización de género -cuidados y educación- gracias a estas medidas, la tendencia comenzó a variar cuando algunas de ellas accedieron a facultades hasta entonces exclusivas para hombres (Maravall, 2012: 27).

Muchas de estas revindicaciones y medidas pioneras entraron en serio retroceso con el golpe de Estado en 1973. A la la represión, la tortura y el exilio le siguió una recesión económica que afectó fundamentalmente a la mujer, con la implementación de políticas neoliberales que aumentaron la exclusión y la desigualdad en el país.

Militantes con y sin carné fueron igualmente perseguidas, hasta que abandonaron el país. Otras, tan sólo la militancia de sus parejas las hizo peligrar y encontraron en el asilo la misma vía de supervivencia que sus compañeras. Ya en el exilio, se volcaron en las acciones de resistencia contra la dictadura. Algunas, volvieron a los pocos años a luchar en el propio país. Pero la mayoría se quedó tratando desde el extranjero de visibilizar en el mundo, los horrores de la dictadura de Pinochet.

Las exiliadas siguieron desempeñando su activismo politico, si cabe con más intensidad que, en Chile, ya que el contexto de libertad y apoyo extranjero, favoreció un clima de mayor seguridad para retomar la lucha contra la dictadura. En esta linea, su actividad opositora se centró primordialmente en la denuncia internacional de las violaciones de los derechos humanos en Chile y en la captación de fondos para el apoyo de la militancia que seguía operando en el extranjero (Maravall, 2012: 107). 
Las mujeres que militaron partidos políticos chilenos en el exilio, trabajaban organizando eventos para recaudar fondos y enviarlos a los partidos chilenos en la clandestinidad. Cada filial del partido en el país receptor, tenía un objetivo definido. Además de la organización interna, las mujeres participaron en las comisiones de prensa y de activismo, porque en tiempos en que no existía Internet, toda la difusión estaba en los medios de comunicación, que cubrían la actualidad de Chile y las acciones de denuncia que se realizaban constantemente desde el exilio.

Esta organización política se mantuvo principalmente en países del exilio donde existía una afinidad con la Unidad Popular. En estos casos, las exiliadas no sólo mantenían su militancia, sino que además el partido les asignaba roles de responsabilidad similares a los que tenían en Chile.

Sali de Chile como jefa de las mujeres de la Unidad Popular y con otra senadora, empezamos a organizar de nuevo a las mujeres jlas mujeres chilenas son tremendas, hay que andar atajándolas para que no se organicen! Empezamos a enviar cartas con nuestras firmas para dar la autorización necesaria para la organización en los sitios donde sabiamos que habia mujeres, y muy poco tiempo después tuvimos ya organización como Unidad Popular de las Mujeres del Exilio, que yo dirigía desde Alemania. (Extracto del testimonio de María Elena Carrera, senadora socialista exiliada en 1974 en Perú, Cuba y posteriormente en la RDA, Oñate y Wright, 2002: 213).

En Madrid, un grupo de exiliadas junto a otros chilenos que tenían experiencia en lo social, organizaron las primeras casas de acogida para mujeres víctimas de violencia a finales de los años setenta. Muchas exiliadas recuerdan la labor de Alicia Herrera, feminista, que abrió junto a integrantes del Partido Obrero Socialista Español, estas primeras casas de acogida en el sur de Madrid.

Otras mujeres chilenas, aprovechando sus conocimientos de docencia, partiparon desde un principio en instancias alternativas de educación como la Escuela Popular de La Prospe, que arrancó en 1973, en el barrio obrero de Prosperidad, en Madrid.

Uno de mis primeros trabajos fue como profesora de castellano en la escuela popular del barrio de La Prosperidad, un barrio obrero en el corazón de Madrid. Haciamos de todo, tengo que reconocer el esfuerzo que significaba para muchos hombres y mujeres venir a clases 3 horas en la noche, después de su jornada 
laboral (María Inés Herrera, exiliada en Madrid desde 1979, militante socialista en entrevista concedida a la investigadora el 10.02.18).

Eran años en que la efervescencia cultural y el feminismo -a principios de los ańos 80 en Madrid- confluían, por eso Emma Landaeta, exiliada chilena que había ya vivido en Argentina, Francia y en Alemania, descubrió cuando llegó a España que estaba todo por hacer y junto a otras compañeras, fundó un grupo de mujeres socialistas que buscaron en la cultura, la manera de seguir con el activismo político.

Fundamos el grupo Ralún, donde trabajábamos con mujeres socialistas, en la elaboración de una revista que reivindicaba el feminismo. En el comité estábamos puras extranjeras, chilenas, argentinas, hasta una colombiana. No es que en nuestros países la cosa fuera distinta a lo que encontramos aqui, los españoles eran igual de machistas que los latinos, pero teníamos experiencia en activismo, asociaciones y en organizar grupos de discusión, manifestaciones, y eso lo aprovechamos (Emma Landaeta, exiliada en Madrid desde 1980, en entrevista con la investigadora el 7.06.18).

No importa si las exiliadas luchan contra la dictadura o reivindican los derechos de la mujer, desde una militancia formal o si lo hacen desde el activismo informal. Todas transmiten en sus testimonios un imperativo ético de denuncia contra las injusticias de las dictaduras que las obligaron a desterrarse y simultáneamente establecen una llamada a la lucha por la igualdad de la mujer, lo que para Nancy Fraser $(2009,114)$ constituye «la génesis de un feminismo transnacional», que será a su vez el «germen» de las primeras políticas públicas de género en estos países.

\section{Conclusiones}

El golpe de Estado protagonizado en 1973 por el general Pinochet, va a cambiar radicalmente el curso de la historia de Chile. No sólo por la crueldad de su estela de muerte y desaparición que dejó en 17 años, sino porque el impacto quizá menos dimensionado de aquella dictadura que se prolongó hasta 1990, fue el exilio de alrededor de 400.000 chilenos, que tuvieron que emigrar intempestivamente a países de acogida en los cinco continentes. 
El golpe termina con el gobierno de la Unidad Popular, un proceso colectivo donde participan activamente los jóvenes que, influidos por el determinismo de la generación del 68, quieren ser sujetos activos de este cambio. Pero también las mujeres, estudiantes y trabajadoras, que sintonizan con el programa de gobierno que promete mayores cuotas de representación, facilidades para el acceso a la educación y la sanidad, y una serie de medidas sociales que influyen como nunca antes en la historia de Chile, en el proceso de emancipación de la mujer.

Quienes escaparon a las ejecuciones o a la desaparición, partieron al exilio gracias a las solidarias muestras de acogida a toda esa población dispersa en el mundo por parte de la comunidad internacional. Sin embargo, los países de acogida recibieron de distinta manera a las familias de exiliados chilenos. No fue la misma recepción en los países con estados benefactores tales como en Francia, Suecia, Dinamarca o Noruega que en países limítrofes o en la península ibérica, donde la figura del refugiado aún no estaba consolidada.

Dentro de esta situación, se ha realizado para este artículo un análisis a la vivencia del exilio femenino, que representó el 30\% de las personas que tuvieron que abandonar Chile. Asumiendo la situación de exclusión y marginación que ha sufrido la mujer en la historia, la investigación que se describe en curso, pretende incorporar esas memorias plurales, provenientes de las minorías, que ayudan a desmitificar el blanqueo de la narativa nacional.

La memoria de las mujeres exiliadas constituye en este caso, la memoria de la otredad, de la alteridad, las marcas en sus testimonios contradicen al discurso oficial -tanto al relato de la dictadura como el elaborado por las voces masculinas- y unifican la reivindicación de la lucha contra la dictadura, con la lucha por los derechos de la mujer. Las mujeres resisten su asimilación a la representación hegemónica, subvierten las convenciones establecidas, no ignoran las injusticias y circulan contra la corriente dominante.

En los testimonios de exiliadas recogidos para esta investigación, pueden advertirse ciertas marcas que desvelan relatos paralelos al relato épico registrado en clave masculina, que hacen más atractivo el conocimiento de lo que pasaba al interior de las comunidades de exiliados chilenos y de sus familias. Esos comportamientos, demuestran un mayor pragmatismo a la hora de resolver las cuestiones cotidianas y una mayor habilidad a la hora de tender lazos familiares tanto con el país de origen (permanencia de estos lazos), como de forjar nuevas redes en el país del exilio. 
El exilio de un número importante de estas mujeres, estuvo antecedido por largos procesos de prisión y tortura cuyas consecuencias físicas y psicológicas se vieron amplificadas al llegar a un país de idioma y culturas distintas. Muchas exiliadas, se cambiaron de país al sentir este rechazo en las sociedades iniciales de acogida, donde se sintieron más acompañadas por otros chilenos en el exilio o por organismos internacionales que hicieron más grata la recepción. En los casos en las que las exiliadas llegaron a un país donde se estaba produciendo un proceso de emancipación de la mujer importante -Canadá, socialdemocracias escandinavas- se produjo una liberalización de su papel reproductivo y la mujer accedió a los beneficios de esa emancipación tales como responsabilidades compartidas en el hogar y la posibilidad de seguir estudiando o trabajar, en condiciones de igualdad.

Desde el punto de vista de las relaciones familiares y afectivas, muchas de las exiliadas sufrieron un quiebre, al enfrentarse a una situación para la que la pareja no estaba preparada tal como la independencia laboral anteriormente descrita. Ante las separaciones, las mujeres se quedaron con la crianza de los hijos, algo que les significó una postergación de su proyecto de vida laboral, acorde con su nivel de estudios, pero pocas veces el abandono de ese proyecto. Esto significó que muchas tuvieron que desempeñarse al principio en trabajos precarios en el sector servicios, para traer el único sustento a la familia. El cuidado de los hijos fue en la mayoría de los casos, exclusiva responsabilidad de la mujer en las sociedades de acogida más tradicionales, aún en los casos en los que no hubo ruptura familiar: fueron ellas las que se preocuparon de la escolarización en el nuevo país y de aprender el idioma nativo.

Tras el fin técnico del exilio, en 1988, el retorno no estuvo inmediatamente en la mente de la mayoría de las exiliadas. La duración prolongada de la dictadura, la existencia de hijos en edad adolescente, el temor a perder beneficios sociales en el país de recepción, el desencanto de partir nuevamente desde cero a nivel de redes sociales y la falta de garantías en sanidad y educación para sus hijos en Chile, hizo que la mayoría pensaran en quedarse. Con el tiempo, tras la jubilación, las exiliadas han tenido más tiempo para dedicarle a proyectos postergados, pero también al activismo que siempre guarda relación con Chile u organismos relacionados con la defensa de los derechos humanos en sus países de acogida. También han sido las exiliadas, las encargadas de mantener los lazos familiares con la familia que quedó en Chile, al principio a través de cartas, llamadas, ahora, a través de las redes sociales. 
En el caso de las militancias, las mujeres que pertenecían un partido político en Chile, continuaron con su militancia en el exilio, esta vez enfocada en labores de recaudación de fondos para la resistencia y en la denuncia y difusión de los crímenes de la dictadura, para concienciar a la opinión pública internacional. Las que no poseían una militancia formal, igualmente vieron desarrollado su activismo político en el exilio que se manifestó también en el trabajo con organizaciones sociales del país de acogida, realializando importantes aportes en el ámbito de la educación y el activismo feminista, por citar los casos estudiados.

A 45 años del hito que cambió para siempre sus vidas, las exiliadas chilenas piden el reconocimiento a una fuerza de trabajo que les permitió salir adelante en situaciones adversas, a los aportes realizados en la comunidad de acogida, y a la labor de resistencia al régimen desde fuera. Un reconocimiento que, aunque llegue tarde, les lleve más allá de ser «las mujeres, las madres o las hijas de».

\section{Bibliografía}

Aguiló, M. (2010). El edificio de los chilenos. (Documental, Chile, 95 minutos)

Alexiévich, S. (2015). La guerra no tiene rostro de mujer, Barcelona: De Bolsillo.

Bambirra, V. (1971). «La mujer chilena en la transición al socialismo». Revista Punto Final, Santiago de Chile, junio.

Bolzman, C. (1993). «Exilio, familia y juventud». En: Montupil, Fernando (director). Exilio, derechos humanos y democracia. El exilio chileno en Europa, Bruselas: Encuentro Europeo de los Comités Pro-Retorno, pp. 45-51.

Brunet, L. (2018). Ardilla, los hilos rojos de mi memoria, Barcelona: Bubok.

Cabrejas, G. (2004). «Transformación de la sociedad española desde 1970: Cambios y permanencias en la institución familiar», Actas de las VI Jornadas de Castilla-La Mancha sobre Investigación en Archivos, Guadalajara, vol. 2, pp. 5-8.

Castillo, C. (2007). Calle santa Fe (Documental, Francia-Bélgica-Chile, 163 minutos).

Corbalán, A. (2016). Memorias fragmentadas. Una resistencia transatlántica a la resistencia femenina contra las dictaduras, Madrid: Iberoamericana.

Eastmond, M. (1997). The Dilemmas of Exile. Chilean Refugees in the U.S.A., Estocolmo: Acta Universitatis Gothoburgensis.

Eltit, D. (1994). Crónica del sufragio femenino en Chile, Santiago de Chile: Servicio Nacional de la Mujer.

ÉNDOXA: Series Filosóficas, n. 44, 2019, pp. 155 - 184. UNED, Madrid 
Espinoza, C. (2005). «Chile en el corazón» monográfico «Exilio y Retorno» de la serie de cuadernos Nosotros los chilenos, Santiago de Chile: LOM.

Espinoza, C.; Ormeño, I., VAldés, K. (2008). La alegría de los otros (Documental, Chile, España, 45 minutos).

Fraser, N. (2009). Scales of justice: Reimagining Political Space in a Globalizing World, New York: Columbia UP.

Hirsch, M. (2015). La generación de la posmemoria: escritura y cultura visual después del Holocausto, Madrid: Carpenoctem.

Horvitz, M. (ed.) (2017). Exiliados y desterrados del Cono Sur de América 1970-1990, Santiago de Chile: Erdosain.

Maravall, J. (2012). Las mujeres en la izquierda chilena durante la Unidad Popular y la Dictadura Militar, Tesis doctoral Universidad Autónoma de Madrid. Madrid.

Martínez, J. (2007). Exiliadas: Escritoras, Guerra Civil y memoria, Madrid: Montesinos.

Oñate, R.; Wright, T. (2002). La diáspora chilena. A 30 años del golpe militar, Ciudad de México: Urdimbre.

Peris Blanes, J. (2008). Historia del testimonio chileno. De las estrategias de denuncia a las politicas de la memoria, Valencia: Quaderns de Filologia, Anejo, 64.

Pinto, J. (ed.) (2005). Cuando hicimos historia. La experiencia de la Unidad Popular, Santiago de Chile: LOM.

Rebolledo, L. (2010). Mujeres exiliadas. Con Chile en la memoria, Santiago de Chile: Universidad de Chile.

Sсотт, J. (1992). «Women's History». New Perspectives on Historical Writing, University Park: Pennsilvania UP.

Soто, O. (1998). El último día de Salvador Allende, Madrid: País Aguilar.

Soто, O. (2013). «Los valores de Salvador Allende son la antítesis de lo que sucede ahora». http://www.nuevatribuna.es/content/print/organizaciones-espanolasy-chilenas-rinden-homenaje-allende/2013090418411296132 [Consultado el 04/09/13]

STERN, S. (2001). «De la memoria suelta a la memoria emblemática: hacia el recordar y el olvidar como proceso histórico (Chile, 1973-1998)» en: M. Garcés et al. (comp.). Memoria para un nuevo siglo. Chile, miradas a la segunda mitad del siglo $X X$, Santiago de Chile: LOM Ediciones.

VV.AA. (2013). El asilo francés a 40 años del golpe de estado, Santiago de Chile: LOM. 
VALDÉs, X. (2000). «El movimiento social de mujeres: memoria, acción colectiva y democratización en Chile en la segunda mitad del siglo XX». En: M. Garcés et al. (comp.). Memoria para un nuevo siglo. Chile, miradas a la segunda mitad del siglo $X X$, Santiago de Chile: LOM Ediciones.

Winn, P. (2013). La revolución chilena, Santiago de Chile: LOM.

Recibido: 16/05/2019

Aceptado: 15/09/2019

\section{(9) $\Theta \Theta \Theta$}

Este trabajo se encuentra bajo una licencia de Creative Commons Reconocimiento-No Comercial-SinObraDerivada 4.0 
